\title{
MATING DISRUPTION WITH PHEROMONES FOR CONTROL OF MOTH PESTS IN AREA-WIDE MANAGEMENT PROGRAMMES
}

\author{
R. T. CARDÉ \\ Department of Entomology, University of California, \\ Riverside, California 92521,USA; carde@ucr.edu
}

\begin{abstract}
SUMMARY
Mate finding in many insect groups is mediated by pheromones, particularly among moths where the male flies upwind along the pheromone plume to a calling female. The use of a formulated, synthetic copy of this message to disrupt this process dates to 1973 with the demonstration of protection of cotton from the pink bollworm Pectinophora gossypiella (Saunders). This method has been expanded to many moth pests, particularly tortricid moths that infest high-value pome fruits and grapes. Because most applications of mating disruptant are not directly lethal, an operational assumption is that efficacy is enhanced when the area under disruption is large enough to mitigate the effects of mated females immigrating into the protected area. Area-wide protocols thus should optimize efficacy of disruption and possibly permit effective control for some highly dispersive species such as heliothine moths that are unlikely to be controlled only by mating disruption in farms of even multiple hectare size. Successful area-wide programmes considered include those for the pink bollworm, codling moth Cydia pomonella (L.), oriental fruit moth Grapholita molesta (Busck), navel orangeworm Amyelois transitella (Walker), European grapevine moth Lobesia botrana (Denis \& Schiffermüller), and gypsy moth Lymantria dispar (L.). Efficacious control, regardless of the magnitude of the crop area, typically requires an initially low population and therefore integration with other control measures.
\end{abstract}

Key Words: Lepidoptera, mate finding, pheromone plume, codling moth, pink bollworm, European grapevine moth, gypsy moth, oriental fruit moth, navel orangeworm, Sterile Insect Technique

\section{INTRODUCTION}

The French naturalist Jean-Henri Fabre, working with the giant peacock moth Saturnia pyri (Denis \& Schiffermüller) in the 1870s, was one of the first to document that females release an alluring odour that draws in males from many metres downwind. In 1882 the New York state entomologist Joseph Albert Lintner, who was also amazed at the ability of a single female saturniid moth to attract many suitors, proposed that synthetic copies of these chemical messages might serve as a means of 
direct control of moth pests. The realisation of this method, however, had to await development of micro-analytical methods capable of identifying pheromones present in billionths of a gram per female (Roelofs 2016).

At present, female-produced pheromones have been chemically defined for several hundred moth species in many lineages (El-Sayed 2016; Löfstedt et al. 2016). Generally, these messages are comprised of blends of 2-3 components, although some moths apparently use a single component and a few species have blends as complex as 6 chemicals. Using these compounds to interrupt chemically triggered mate finding by males requires methods to gradually release these compounds into the crop to be protected. There are now many kinds of slow-release formulations that protect these usually labile chemicals until their release into the atmosphere.

Harry Shorey and his colleagues at the University of California, Riverside (Gaston et al. 1977) were the first to demonstrate in field trials that application of formulated synthetic pheromone could control a moth pest. In the 1970s, the pink bollworm, Pectinophora gossypiella (Saunders) (Gelechiidae), was a principal pest of cotton grown in southern California's Coachella Valley. Synthetic pheromone was formulated into open-ended, hollow plastic fibres and released at $10 \mu \mathrm{g}$ per fibre per day; fibres deployed by hand at a density of approximately 1 per $\mathrm{m}^{2}$ provided control by reduction in boll damage comparable to conventional practice in the insecticidetreated controls. This success provided an impetus for efforts to develop mating disruption for other key moth pests. Today this method has been commercialized for many of the most economically important moth pests (Evenden 2016) and we term this method of pest control 'mating disruption'. The successes and constraints of the mating disruption technique have been summarized by Cardé and Minks (1995), Cardé (2007), and Evenden (2016). Witzgall et al. (2010) reported that an estimated 770000 ha yearly received mating disruption treatments for moths.

This review will explore the utility of this approach in large-scale applications where the goal of management is either to suppress a pest directly or in some cases, to eradicate a population over an entire region. To understand the prospects for successful disruption in area-wide programmes, it will be useful to consider how a broadcast application of a disruptant interferes with mate finding and how formulation type and a precise matching of the disruptant to the natural pheromone influences efficacy of disruption.

Most moth pheromones are straight-chain, $\mathrm{C}_{10}$ to $\mathrm{C}_{18}$ compounds with either an acetate, alcohol, or aldehyde moiety, and 1-3 positions of unsaturation (El-Sayed 2016; Löfstedt et al. 2016). These chemicals, and generally most other moth pheromones, are subject in the field to degradation by processes such as isomerization, oxidation and polymerization, and consequently one objective of all formulations is to provide protection against degradation while releasing the active ingredients into the atmosphere, ideally at a fairly constant rate until depletion. Most formulations use a plastic matrix (e.g. microcapsules, open-ended hollow fibres, sealed plastic tubes ('ropes'), PVC capsules, laminates, etc.) to retain the disruptant. Other formulations use dollops of a waxy emulsion into which the disruptant is mixed or the disruptant is released as an aerosol in timed puffs from widely spaced, sealed cans (Table 1). 
Table 1. Examples of formulations used in mating disruption of moths (modified from Cardé 2007); the densities and methods of application, field longevities, and probable modes of action are general examples

\begin{tabular}{|c|c|c|c|c|}
\hline Formulation $^{*}$ & Density ha ${ }^{-1}$ & Application method & Longevity & Mode of Action \\
\hline $\begin{array}{l}\text { Atomizer } \\
\text { 'puffer' }\end{array}$ & $<1$ to several & hand-placed & season-long & $\begin{array}{l}\text { sensory impairment; } \\
\text { camouflage; competition }\end{array}$ \\
\hline $\begin{array}{l}\text { Sealed plastic } \\
\text { tubes }\end{array}$ & hundreds & hand-placed & season-long & $\begin{array}{l}\text { sensory impairment; } \\
\text { camouflage; competition }\end{array}$ \\
\hline $\begin{array}{l}\text { Open-ended, } \\
\text { hollow fibres, } \\
\text { laminate 'flakes' }\end{array}$ & $\approx 10000$ & aerial & weeks & $\begin{array}{l}\text { sensory impairment; } \\
\text { camouflage; competition }\end{array}$ \\
\hline Waxy dollops & $100-10000$ & $\begin{array}{l}\text { hand-applied, } \\
\text { aerial, speciali- } \\
\text { sed equipment }\end{array}$ & $\begin{array}{l}\text { weeks to } \\
\text { season-long }\end{array}$ & $\begin{array}{l}\text { sensory impairment; } \\
\text { camouflage; competition }\end{array}$ \\
\hline $\begin{array}{l}\text { Microcapsules } \\
\text { spray }\end{array}$ & millions & conventional & $\begin{array}{l}\text { days to several } \\
\text { weeks }\end{array}$ & $\begin{array}{l}\text { sensory impairment; } \\
\text { camouflage }\end{array}$ \\
\hline $\begin{array}{l}\text { 'Attracticide' } \\
\text { (e.g. fibres with } \\
\text { insecticide in sticker) }\end{array}$ & $\approx 1000$ & $\begin{array}{l}\text { specialized } \\
\text { equipment }\end{array}$ & weeks & $\begin{array}{l}\text { direct toxicity; impairment } \\
\text { of orientation; competition }\end{array}$ \\
\hline
\end{tabular}

* When the formulation is not comprised of the full (attractive) pheromone blend or it contains an antagonist, it may not evoke competition (for an example see Section 3.3)

In field applications these differing formulation types produce a large range of densities of disruptant sources and release rates and consequently in the atmospheric concentrations and spatial distributions they generate. Some formulations are point sources that match or exceed the attractiveness of a calling (pheromone-emitting) female. Other disruptant formulations are either intrinsically non-attractive because they are an incomplete copy of the pheromone blend (lacking components required for good attraction), or they contain synthetic by-products that are antagonistic and so either reduce or even eliminate attractiveness of the formulated product (Cardé 2007).

As formulations can be expected to be applied repeatedly to the same area and therefore themselves could be a source of pollution, a formulation's degradability over time should be a factor in its selection.

\section{MECHANISMS OF MATING DISRUPTION}

Disruptants can interfere with mate location in 3 principal ways:

1. Competition: Males may spend time and energy orienting to sources of formulation. The efficacy of this mechanism should be dependent on the ratio and comparative attractiveness of these sources to calling females (see Miller et al. 2006 for a theoretical consideration of this mechanism). A variant on this method adds insecticide to point sources of pheromone, an "attract and kill" strategy (Cork 2016). 
2. Sensory Impairment: Exposure of males to disruptant causes either a diminution in responsiveness by raising the threshold for response, or by altering navigational ability, or exposure may simply eliminate responsiveness to the pheromone. Generally, such impairment can be due to adaptation of either sensory receptors or habituation, which is a central nervous system phenomenon, or both factors.

3. Camouflage: The pheromone plume from a calling female becomes imperceptible amongst the background of disruptant.

When the formulation mimics the natural pheromone, all of these mechanisms could contribute to efficacy and they could act additively or synergistically. There are other supplementary ('minor') mechanisms such as delay in mating that also could contribute to efficacy (see for examples: Cardé 2007 and Evenden 2016).

As will be documented, the susceptibility to disruption seems to vary with species, formulation type and application rate (Table 1), and whether the active ingredients match the full natural pheromone. Some of the behavioural traits that promote or interfere with successful mating disruption are listed in Tables 2 and 3.

Table 2. Male behavioural traits expected to confer higher or lower susceptibility to mating disruption matched with moths thought to possess these traits (see Cardé 2007 for further details on mechanisms)

\begin{tabular}{ll} 
Higher Susceptibility & Lower Susceptibility \\
\hline $\begin{array}{l}\text { Readily habituated } \\
\text { [oriental fruit moth] }\end{array}$ & $\begin{array}{l}\text { Difficulty to habituate } \\
\text { [pink bollworm] }\end{array}$ \\
$\begin{array}{l}\text { Slow to dishabituate } \\
\text { [oriental fruit moth, codling moth] }\end{array}$ & $\begin{array}{l}\text { Rapid dishabituation } \\
\text { [pink bollworm] }\end{array}$ \\
$\begin{array}{l}\text { Poor ability to navigate along plumes } \\
\text { within a background of pheromone }\end{array}$ & $\begin{array}{l}\text { Good ability to navigate along plumes } \\
\text { within a background of pheromone }\end{array}$ \\
$\begin{array}{l}\text { Rhythm of response imprecisely } \\
\text { coordinated with female calling } \\
\text { [pink bollworm] }\end{array}$ & $\begin{array}{l}\text { Male and females mating rhythms } \\
\text { well-coordinated }\end{array}$ \\
$\begin{array}{l}\text { Males rely principally on pheromone } \\
\text { for orientation and mating } \\
\text { [pink bollworm] }\end{array}$ & $\begin{array}{l}\text { Visual and tactile cues facilitate } \\
\text { orientation and mating } \\
\text { [oriental fruit moth] }\end{array}$
\end{tabular}

Although formulation type, the match of its active ingredient to the natural pheromone, and its application rate all are quite important to disruption efficacy, ecological factors also are crucial: what is the pest's density at the start of application, does it need to be suppressed to a suitable level before application, and how migratory are mated and unmated females?

The first issue influences efficacy in two ways: the higher the density of moths, the closer they are to each other spatially and phenologically; at very low population densities, both factors should diminish the probability of females mating, essentially an Allee effect, in which a population at very low density could collapse because of a failure to find a mate (Liebhold and Bascompte 2003). 
In most management protocols, it will be necessary to use additional control tactics such as cultural methods (e.g. sanitation) or insecticide application to reduce the population to a level amenable to mating disruption. For those moths that are notable adult nectar feeders (such as noctuids), a bait of adult feeding stimulants laced with insecticide provides another tactic to integrate with mating disruption (Gregg et al. 2018).

Moth movement is a second ecological factor to consider. If the species is highly migratory (such as many heliothine moths) and the area under management is near a source population, then the area under mating disruption may suffer crop damage due to the immigration of mated females. Possibly too, virgin females could leave an area under disruption, mate, and then reinvade the crop. The density and proximity of the outside population and the tendency of mated females to migrate should govern in part the programme's success. Migratory tendency and capability vary considerably among moth species and, even within a species, migration can be modulated by changes in crop suitability and season. Application of the principles of density and movement will be useful to interpreting several case studies.

Table 3. Female behavioural traits expected to confer higher or lower susceptibility to mating disruption matched with moths thought to possess these traits (see Cardé 2007 for further details on mechanisms)

\begin{tabular}{ll} 
Higher Susceptibility & Lower Susceptibility \\
\hline $\begin{array}{l}\text { Low pheromone emission rate } \\
\text { [oriental fruit moth] }\end{array}$ & High pheromone emission rate \\
$\begin{array}{l}\text { Calling from within } \\
\text { plant canopy }\end{array}$ & $\begin{array}{l}\text { Calling from top of canopy } \\
\text { [pink bollworm] }\end{array}$ \\
$\begin{array}{l}\text { Rhythm of response imprecisely } \\
\text {-coordinated with female calling } \\
\text { [pink bollworm] }\end{array}$ & $\begin{array}{l}\text { Male and females mating rhythms } \\
\text { well-coordinated }\end{array}$ \\
Low migratory tendency & \\
[North American gypsy moth] & Migratory \\
\hline
\end{tabular}

Of particular relevance to the use of mating disruption in area-wide programmes will be assessing how size and isolation or distance of treated areas from outside infestation influences efficacy. Given the logistical difficulties and cost of evaluating whether area-wide programmes enhance management of a 'keystone' moth pest over conventional field-by-field or grower-by-grower practices, much of what we can conclude will be by inference rather than by referring to empirical tests.

The following case studies are examples of successful management using mating disruption, often combined with other techniques. Each example is considered briefly and specific documentation of the field evidence pertinent to area-wide use is cited. Mating disruption has been studied in all of the following pest species over many years. 


\section{CASE STUDIES}

\subsection{Pink Bollworm}

The first field-scale use of mating disruption was against the pink bollworm, Pectinophora gossypiella (Gaston et al. 1977), and in 1978 it was the first pheromone to be registered by the USA Environmental Protection Agency (US-EPA) as an insecticide. The active ingredients are a 1:1 mix of the two components of the female's pheromone, $(Z, Z)$ - and (Z,E)-7,11-hexadecadienyl acetates. There are now several formulation products in use (e.g. hollow fibres, sealed plastic 'ropes').

There is one notable field study of its use in area-wide management. In Arizona in the 1970s, control of this pest relied largely on frequent night-time aerial sprays of insecticide aimed at the adult moth. This approach was becoming untenable, because of increasing insecticide resistance and costs. The Parker Valley is isolated from other cotton-growing areas by surrounding desert (Fig. 1), thereby eliminating influx of mated females from outside the treated area and thus constituting an ideal location to evaluate an area-wide programme. Growers in the Parker Valley of Arizona, in collaboration with the Animal and Plant Health Inspection Service (APHIS) arm of the United States Department of Agriculture (USDA), devised a multi-year programme to attempt to directly manage pink bollworm with mating disruption and some use of insecticide in all cotton fields (detailed in Staten et al. 1996).

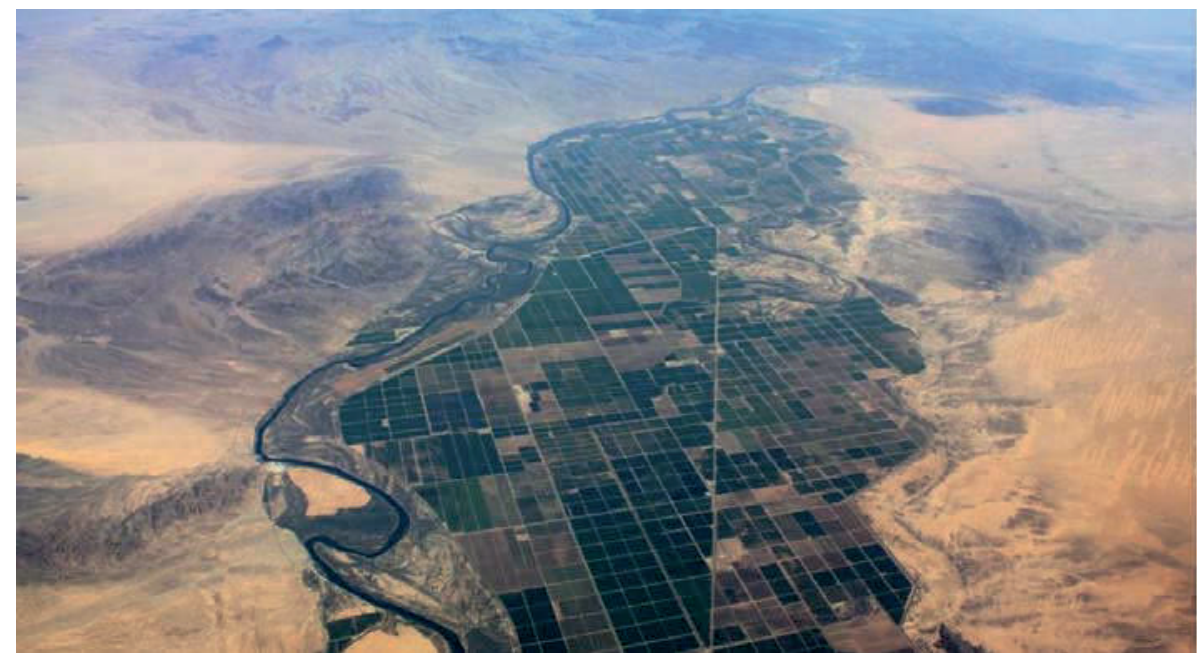

Figure 1. Aerial view of the Parker Valley agricultural area along the Colorado River in Arizona. The growing area was well isolated from other cotton production by surrounding desert (courtesy Google Maps).

Parker Valley's 11250 ha of cotton comprised a significant size and, prior to this programme, intensive application of insecticide provided unacceptable levels of control ( $>25 \%$ boll infestation in the year prior to the programme's start). Mating disruptant applications began in 1990 and the programme ended in 1993. Throughout, 
approximately one third of the cotton received a hand application of rope dispensers and the rest of the applications were by air and used fibres or fibres plus an insecticide overspray.

Over the project's four-year span, the use of insecticide dropped from half of the aerial applications to less than a tenth. There were approximately 650 fields in the programme and 45 of these were selected at random for assessing boll damage. From 2000 to 3000 cotton bolls were cracked weekly to check infestation. The highest recorded weekly larval count per boll was $21 \%$ in 1990 , dropping to $7 \%$ in $1991,2 \%$ in 1992 and zero in 1993, when over 20000 bolls were examined season-long and not a single pink bollworm larva was found. Clearly this technology offered a new paradigm for management of a pest that was becoming very difficult to control with conventional insecticides. One remarkable feature of this demonstration was that it succeeded even though initial infestation levels were high and this species is considered rather migratory (Stern 1979). These sorts of programmes lack replication and direct experimental controls, but the substantial infestation levels across the Parker Valley in the years prior to the programme serve to verify efficacy. Despite the success of this programme, mating disruption for pink bollworm is now in limited use worldwide $(\approx 50000$ ha annually according to Witzgall et al. (2010), or $\approx 3 \%$ of cotton worldwide), mainly due to the availability of Bacillus thuringiensis (Bt)-cotton, which has supplanted mating disruption and conventional insecticides for control of this and other moths.

Mating disruption also played a central role in the successful area-wide effort to eradicate pink bollworm from the south-western USA (Texas to California) and adjoining areas in northern Mexico. This audacious undertaking was reviewed by Lance et al. (2016). The programme began in 1994 and involved at various stages and regions the application of mating disruptant, release of sterile moths, some application of insecticides and, beginning 1997-1998, planting of Bt-cotton. Since 2008 no larvae have been detected anywhere in the entire cotton-growing regions of the southwestern USA and northern Mexico (Staten and Walters, this volume). The success of this programme (which continues with monitoring using pheromone traps) is difficult to attribute to any single control technique and it is most probable that the combination of methods was needed to suppress reproduction. Its success was likely also guaranteed by the integration of these methods on an area-wide basis over all cotton growing areas in the region and the fact that this moth is a cotton specialist.

\subsection{Codling Moth}

Cydia pomonella (L.) (Tortricidae), infests many kinds of pome fruits and walnuts, and it is particularly troublesome in apple orchards. Most work has characterised its pheromone as a single component $(E, E)-8,10$, dodecadienol. Probably more field tests on mating disruption have been conducted on this species than any other moth. As of 2010, about 210000 ha were treated yearly with mating disruptant for this pest worldwide (Witzgall et al. 2010). A general conclusion is that this species is difficult to disrupt in the sense that for success initial populations need to be low and isolated from the influx of mated females from untreated areas; in any case, growers will not tolerate more than a small percentage of fruit damage. 
Witzgall et al. (2008) reviewed these studies and provided two general conclusions: 1) prior to treating with disruptant, initial populations must be low and therefore a remedial application of insecticide or some other method could be necessary to achieve the desired population level; and 2) the larger the area under pheromone management and the greater its isolation from outside sources of infestation, the greater the level of protection and economic benefit per hectare (McGhee et al. 2011). Given that apples typically are produced in orchards of varying size and proximity to other orchards and non-commercial hosts (a 'patchwork' pattern), coordination of a common strategy across many growers in a region is a logistical and sociological challenge (Brunner et al. 2002).

No definitive field studies have established the minimum plot size for maximum achievable efficacy (i.e. the point where no further reduction in mating can be expected) and certainly efficacy will vary somewhat with application rate and formulation type (e.g. puffers vs. hand-applied, point-source), how thoroughly the formulation disperses disruptant throughout the canopy, canopy structure, initial population density, climate, and topography (see Witzgall et al. 2008). The principal lessons to be drawn from numerous field studies with codling moth are that for mating disruption to succeed, initial populations must be very low (if need be requiring remedial treatment with an insecticide) and sufficiently isolated from sources of mated females.

\subsection{Oriental Fruit Moth}

Grapholita molesta (Busck) (Tortricidae) is a troublesome pest on peaches, pears, nectarines, plums and apples; its first generation also can inflict significant damage to shoot tips. Its pheromone is a 3-component blend: $(Z)-8$ - and $(E)$-8-dodecenyl acetates (95:5) with $3-10 \%$ of (Z)-8-dodecenol added. This moth seems especially susceptible to mating disruption, with a wide variety of formulation types (microdispersibles to aerosol puffers) of the pheromone providing excellent fruit protection (Cardé 2007; Evenden 2016). As of 2010, about 50000 ha were treated yearly with mating disruptant for this moth (Witzgall et al. 2010).

In Australia, Il'ichev et al. (2002) set out to establish that an area-wide approach would provide enhanced control over an orchard-by-orchard management. In the project's first year an area of over 800 ha including 18 orchards were treated with hand-applied dispensers at 1000 per ha; in the second year over 1000 ha comprising 40 orchards were treated with 500 dispensers per ha.

In the first year, growers decreased insecticide application by half and during the second year most growers did not apply any insecticides for this pest. Areas previously identified as 'hot spots' of infestation also were brought under control. Il'ichev and colleagues concluded that area-wide management with pheromone was highly effective for oriental fruit moth, but cautioned that infestations could linger at the edges of disruptant-treated blocks if the permeation of air-borne disruptant there was incomplete due to wind patterns or if neighbouring orchards harboured oriental fruit moths (Il'ichev et al. 2002). 


\subsection{European Grapevine Moth}

The pheromone of Lobesia botrana (Denis \& Schiffermüller) (Tortricidae) is usually considered to be a single compound, $(\mathrm{Z}, E)-7-9$-dodecadienyl acetate. Historically this moth has been a grape pest in Southern Europe, North Africa, Anatolia and the Caucasus; it was recently introduced into South America (Taret et al., this volume). As of 2010, Witzgall et al. indicated that 100000 ha in the European Union, Argentina and Chile were treated yearly with mating disruptant for this moth.

In 2009, it was discovered in northern California with a nexus in Napa County. Following the discovery of this pest, its distribution was mapped in 2010 with a network of traps throughout the grape growing regions of California. Over 100000 males were trapped, mainly in Napa County, but with significant populations in adjoining Sonoma County, and isolated pockets elsewhere, these being attributed to movement of material such as stakes from the original area of infestation rather than natural dispersal. A multi-pronged eradication programme with support from growers and organizational direction from federal, state, county and extension agencies was initiated in 2011 (for detailed reviews see Lance et al. 2016, and Simmons et al., this volume).

In 2011 and 2012, mating disruptant was applied to $\approx 160 \mathrm{~km}^{2}$ in Napa County, generally in the core-infested area, and to $\approx 16 \mathrm{~km}^{2}$ in Sonoma County, with smaller application areas in 2013 and 2014. Since 2015, extensive pheromone trapping has not caught any males, and the moth has been declared eradicated. It is fair to note that conventional insecticides were used in many but not all vineyards. Therefore, the areawide demise of this pest cannot be attributed solely to mating disruption, but it was viewed as a key component of successful eradication (Lance et al. 2016).

\subsection{Navel Orangeworm Moth}

Amyelois transitella (Walker) (Pyralidae) is a key pest of almonds, pistachios and walnuts in California. This moth can be controlled using mating disruption as part of an integrated pest management programme. Aerosol dispensers, deployed at one per 0.8 ha, emit (Z,Z)-11-13-hexadecadienal, one of the 4-components of its pheromone, but which alone is at best slightly attractive compared to the full blend. Mating disruptant generally provides control levels similar to insecticide-alone regimes and the combination of disruption and insecticide generally resulted in better pest management and even lower levels of damage (Higbee and Burks 2008).

Based on flight mill studies, virgin navel orangeworm females appear capable of migrating several km (Sappington and Burks 2014), although whether mated females would naturally migrate such distances when they are within a host orchard remains to be determined. Evidence that such moderate-distance migration is an important consideration stems from the field study of Higbee and Seigel (2009), who found that navel orangeworm damage in almond blocks was correlated with distance from pistachios (with traditonally higher populations): some spillover was detectable even with a 5-km separation. The migratory capacity of navel orangeworms demonstrated so far suggests that crop protection should be enhanced as the area under treament is scaled up. 
In California, almond and pistachios orchards often extend in contiguous plantings over many $\mathrm{km}$ and therefore movement of mated females from untreated orchards to adjoining blocks treated with disruptant is probable. This pest is an ideal candidate for an area-wide management programme using mating disruption. Careful monitoring in a 4-year demonstration project in 1050 ha of almonds, showed that 3 insecticide sprays yielding $5-10 \%$ damage could be replaced by mating disruption, producing only $0.5 \%$ damage (Higbee 2010). Registration and use of its complete pheromone blend might provide higher levels of nut protection than the currently used aldehyde (Higbee et al. 2017). Another rationale for area-wide application is that several percent nut damage occured in 16-ha mating disruptant plots (Higbee et al. 2017); presumably, increasing greatly the area under disruption would enhace protection by limiting influx of mated females. Overall, in 2016 mating distuption was used in California on over 80000 ha of almonds and pistachios (Higbee personal communication).

\subsection{Gypsy Moth}

The potentially expanding range of the gypsy moth, Lymantria dispar (L.) (Erebidae), in North America and introductions of its Asian form are monitored by a network of more than 200000 pheromone traps (Lance et al. 2016). Traps are baited with the pheromone, $(7 R, 8 S)$-cis-7,8-epoxy-2-methyloctadecane, called '( + )-disparlure', but, as optically pure disparlure is quite expensive, the $(+)$ - enantiomer is only used in survey lures. Mating disruption uses the inexpensive racemate as a disruptant. The racemate is about one tenth as attractive because its (-)-enantiomer is an antagonist of attraction.

Aerially applied racemic disparlure is being used to retard the advance of gypsy moths to the south and west of low-level populations along the edge of its advancing USA range. Mating disruption is deployed in a $100-\mathrm{km}$-wide band from North Carolina to Minnesota in a programme called "Slow the Spread" (reviewed by Lance et al. 2016; Liebhold et al., this volume). In this zone, trap capture is low (between 01 per trap yearly throughout most of the band, rising to several or more per trap near the edge adjoining the established population). Prior studies have established efficacy of aerially applied formulations (e.g. Thorpe et al. 2006), verified by substantial reductions in capture in pheromone-baited traps in subsequent years and mating of tethered, sentinel females.

From 2000 to the present, an average of about 180000 ha have been treated yearly (Lance et al. 2016). The migration biology of the North American gypsy moth differs from most moths in that the female is flightless and natural population spread occurs through wind-borne 'ballooning' of first instar larvae. (Anthropogenic transport, particularly of egg masses, remains an important regulatory and practical issue.) Thus, female movement does not influence the success of mating disruption in a given area. Larval movement (ballooning $1^{\text {st }}$ instars), however, will influence the size of the area wherein mating disruption will be effective. 


\section{IS EFFICACY INFLUENCED BY THE SIZE OF THE AREA TO BE TREATED?}

A reoccurring theme in all studies of mating disruption is the assumption that the larger the plot size, the more efficacious mating disruption, because large size mitigates the influx of mated females from outside the treated area. Experimental evaluation of formulations and active ingredients for efficacy can be accomplished, at least with some moths, with replicated small plots (ca. 25 by $15 \mathrm{~m}$ ) (Roelofs and Novak 1981) and with small field cages (ca. $8 \mathrm{~m}^{3}$ ) (Koch et al. 2009) by testing for disruption of attraction to pheromone lures and to females. It is generally accepted that proof of crop protection, however, needs to be assessed in replicated plots that are large enough to minimize or eliminate the immigration of mated females from untreated areas, whereas disruption of attraction to a lure or female in a trap are insufficient metrics. There have been several notable studies using replicated large plots [Brockerhoff et al. 2012 with the light brown apple moth, Epiphyas postvittana (Walker); Onufrieva et al. 2018 with the gypsy moth; and Higbee and Burks 2008, Higbee et al. 2017 with the navel orangeworm moth]. With such large experimental plots, some useful information on the infiltration of mated females may be found by monitoring infestation or disruption levels from a plot's edge to its centre.

As the distance that mated females migrate varies with species and also can be influenced by habitat, host availability and season, there is no set answer as to how large a plot needs to be to guard against such immigration from the periphery. What is clear is that efficacy should be enhanced with enlarged treatment areas and becomes optimal if all areas that harbour the population of the pest are treated. Crucial to understanding these interactions will be characterisation of the moth's migratory capacity and the conditions in the field that trigger this behaviour. There are not, however, replicated field experiments that have defined optimal plot size directly, and given the sizes required, these are unlikely to be undertaken.

\section{INTEGRATION OF MATING DISRUPTION WITH STERILE INSECT RELEASE}

The Sterile Insect Technique or SIT is another environment-friendly method for insect suppression and in some cases eradication (Dyck et al. 2021). The SIT efficacy is largely contingent on the ratio of sterile to native insects (the overflooding ratio) and the competitiveness of sterile insects. Because mating disruption seeks to diminish mating success, it seems counterintuitive to combine these two approaches, as application of disruptant would diminish the probability that sterile insects would mate with native insects. However, because both techniques reduce the number of fertile females, in combination they may enhance population suppression over either method used alone. Furthermore, where use of either mating disruption or SIT fails to provide sufficient control (e.g. because of gaps in coverage), then the other method could be employed. There are many examples of incomplete population suppression using mating disruption, even with prior application of conventional insecticides to suppress the population to a low level (e.g. Witzgall et al. 2008; Evenden 2016; Higbee et al. 2017). 
The SIT generally aims to achieve a particular overflooding ratio (e.g. a 10 to 1 ratio of sterile insects to native ones) and one challenge is determining the density of the native population. One method for evaluating a SIT programme is to compare the ratio of internally-marked sterile to native males captured in pheromone traps (Vreysen 2021). A difficulty, however, in combining mating disruption and SIT is that application of disruptants makes the monitoring of population levels and the overflooding ratio with pheromone traps problematic. Of course, absence or very low numbers of trap catch in pheromone-baited traps often is used to verify that male orientation to females is being suppressed and therefore that mating disruption is protecting the crop.

For evaluation of population density in some species (e.g. pink bollworm and codling moth), males can be trapped in mating disruption areas by using a lure with high rate of pheromone emission, that is, 10 -fold higher than would normally be used in population monitoring (Doane and Brooks 1981; Witzgall et al. 2008), and so these high-dose traps could be used for evaluation of the SIT component. In a few cases, there are kairomone lures that are effective in sampling adult moths in mating disruption plots (e.g. Knight 2010; Burks 2017).

The combination of these two methods has of course been limited to those few moth species for which the SIT package and mating disruption have been fully developed and tested for field efficacy. With pink bollworm, aerial release of sterile insects was long used to suppress this pest in the San Joaquin Valley of California, with daily releases of up to 18 million moths. As considered earlier in Section 3.1, mating disruption, SIT and other measures were combined in an ambitious and successful area-wide eradication programme in the south-western USA and northern Mexico (Lance et el. 2016; Staten and Walters, this volume). As both mating disruption, SIT and in the later years $B t$-cotton were combined, it is impossible to parse out the precise contribution of each tactic and especially the extent to which either mating disruption or SIT contribute to suppression. It also is possible that sequential application of these techniques (SIT preceding mating disruption or vice versa) would yield higher levels of eventual suppression than simultaneous application.

The SIT is the mainstay in the management of the codling moth in the Okanagan Valley of British Columbia, Canada (Nelson et al., this volume). Over the past 20 years, this programme has produced a dramatic reduction in insecticide use in apples (some growers have not applied an insecticide for codling moth in 15 years). Fruit infestation is extremely low $(<0.2 \%)$ in $>90 \%$ of the orchards. Like successful programmes using mating disruption with codling moth (Section 3.2), a key factor is early intervention with insecticides to reduce populations to the low levels where SIT can provide a final reduction and continued control (Bloem et al. 2007).

An effort in the same region to combine SIT with mating disruption, Judd and Gardiner (2005) established in organic orchards that these two measures coupled with removal of overwintering larvae using tree bands (cultural control) in concert suppressed codling moths to non-detectable levels within several years. Judd and Gardiner (2005) proposed that mating disruption and SIT together was as effective as SIT and some initial insecticide. 
The area-wide integration of mating disruption with SIT application was also effective south of the Canadian-USA border (Calkins et al. 2000). This finding as well as the successful eradication efforts with pink bollworm both point to a favourable interaction of mating disruption with SIT, but precisely how these two seemingly competitive approaches either complement or interfere with each other remains to be determined.

Whether combining mating disruption and SIT enhances crop protection over either method alone thus remains an outstanding question. Before widespread implementation of these combined tactics, it would be valuable for future programmes to compare in replicated plots the levels of crop protection provided by each technique alone and in combination. Perhaps modelling how these two processes interact would provide insight into the value of combining SIT and mating disruption.

It also might be feasible to develop through either conventional selection or genetic engineering strains for SIT application that have males that are 'resistant' to mating disruption (e.g. by reducing their tendency to habituate response to pheromone, possibly by altering their biogenic amines levels - see Linn and Roelofs 1986). Males from such a strain would be more apt than their wild counterparts to find females amidst a background of mating disruptant. How such males perform in a nondisruptant environment would be important to understand, but presumably such a trait would render modified moths less competitive than their wild counterparts, because this is a trait that would not be favoured under the constraints of traditional natural selection in the field. Presumably, as well, interbreeding with wild moths would not produce offspring.

In field-cage observations using laboratory strains of codling moth, a single encounter with a point source of pheromone can render a moth unresponsive to pheromone for 24 hours (Stelinski et al. 2006). In contrast, the strain of pink bollworm used in the SIT programme remains pheromone responsive ('resistant' to habituation) after a 24-hour exposure to pheromone (Cardé et al.1998). Although we do not know how released sterile pink bollworm males behave in disruptant plots, these observations suggest that they should search for females and therefore the field efficacy of mating disruptants in this strain should be at least partially contingent on a mechanism of competition between pheromone sources from deployed formulations and those from wild and also sterile females.

Cardé et al. (1998), interpreting the mechanisms of mating disruption in the pink bollworm, assumed that wild and sterile pink bollworm males were behaviourally equivalent. An open question, however, is whether continuous exposure to high pheromone levels during many generations under mass-rearing has altered its pheromone response characteristics.

An obvious criterion for evaluating sterile moths is how competitive they are in finding mates. If the SIT is to be integrated with mating disruption, then another criterion may be the ability of sterile males to find wild females amidst a background of disruptant and whether this is a trait that can be enhanced by selection. 


\section{CONCLUSIONS}

The principle and its practical application that formulated pheromone can control many kinds of moth pests are well established. The susceptibility of a given moth pest to mating disruption, however, varies with characteristics of its communication system (e.g. rate of pheromone release from the female, male sensitivity to sensory interference) and formulation rate of release, its match to the natural pheromone, and type (e.g. widely-spaced aerosol dispensers, point sources mimicking females, nonattractive disruptants). The acceptance of this method for management of many species of moths signifies both its efficacy and cost-effectiveness.

Incorporation of mating disruption into area-wide integrated management programmes would seem to be a straightforward process, simply requiring scale-up of established methods, with the benefit that efficacy is expected to be enhanced, given that a large area of application (hundreds of ha) mitigates the influx of mated females from the periphery. One concern in widespread use of mating disruption is that the goal, suppression of mating, also suppresses capture in pheromone-baited traps, which can be a useful tool for population monitoring.

Replicated field demonstrations that the larger the disruptant-treated area, the greater the efficacy of mating disruption generally, however, will remain an elusive and perhaps intractable experimental goal. We will continue to rely on replicated, small-scale trials to establish that formulations are sufficiently efficacious to warrant area-wide application. Ultimately, the success of any area-wide approach depends not just on effective tools for insect control, but cost-effectiveness, environmentfriendliness, social acceptance, and management protocols for implementation (Hendrichs et al. 2007).

\section{ACKNOWLEDGEMENTS}

I thank Charles Burk, Brad Higbee and Greg Simmons for providing valuable comments and suggestions.

\section{REFERENCES}

Bloem, S., A. McCluskey, R. Fugger, S. Arthur, S. Wood, and J. Carpenter. 2007. Suppression of the codling moth Cydia pomonella in British Columbia, Canada using an area-wide integrated approach with an SIT component, pp. 591-601. In M. J. B. Vreysen, A. S. Robinson, and J. Hendrichs (eds.), Area-wide control of insect pests: From research to field implementation. Springer, Dordrecht, The Netherlands.

Brockerhoff, E. G., D. M. Suckling, M. Kimberley, B. Richardson, G. Coker, S. Gous, J. L. Kerr, D. M. Cowan, D. R. Lance, T. Strand, and A. Zhang. 2012. Aerial application of pheromones for mating disruption of an invasive moth as a potential eradication tool. PLoS One 7(8)343767.

Brunner, J., S. Welter, C. Calkins, R. Hilton, E. Beers, J. Dunley, T. Unruh, A. Knight, R. Steenwyk, and P. Van. 2002. Mating disruption of codling moth: A perspective from the Western United States, IOBC/WPRS Bulletin 25(9): 11-20.

Burks, C. S. 2017. Combination phenyl propionate/pheromone traps for monitoring navel orangeworm (Lepidoptera: Pyralidae) in almonds in the vicinity of mating disruption. Journal of Entomology 110: 438-446. 
Calkins, C. O., A. L. Knight, G. Richardson, and K. A. Bloem. 2000. Area-wide population suppression of codling moth, pp. 215-219. In K. H. Tan (ed.), Area-wide control of fruit flies and other insect pests. University Sains Malaysia. Pulau Penang, Malaysia.

Cardé, R. T. 2007. Using pheromones to disrupt mating of moth pests, pp. 122-169. In M. Kogan and P. Jepson (eds.), Perspectives in ecological theory and Integrated Pest Management, Cambridge University Press. Cambridge, UK.

Cardé, R. T., and A. K. Minks. 1995. Control of moth pests by mating disruption: Successes and constraints. Annual Review of Entomology 40: 559-585.

Cardé, R. T., R. T. Staten, and A. Mafra-Neto. 1998. Behaviour of pink bollworm males near high-dose, point sources of pheromone in field wind tunnels: Insights into mechanisms of mating disruption. Entomologia Expermentalis et Applicata 89: 35-46.

Cork, A. 2016. Pheromone as management tools. Mass-trapping and lure-and-kill, pp. 349-363. In J. D. Allison and R. T. Cardé (eds.), Pheromone communication in moths: Evolution, behavior and application. University of California Press, Berkeley, California, USA.

Doane, C. C., and T. W. Brooks. 1981. Research and development of pheromones for insect control with emphasis on the pink bollworm, pp. 285-303. In E. R. Mitchell (ed.), Management of insect pests with semiochemicals. Concepts and practice, pp. 229-242. Plenum, New York, NY, USA.

Dyck, V. A., J. Hendrichs, and A. S. Robinson (eds.). 2021. Sterile Insect Technique - Principles and practice in Area-Wide Integrated Pest Management. Second Edition. CRC Press, Boca Raton, Florida, USA. 1200 pp.

El-Sayed, A. M. 2016. The pherobase: Database of pheromones and semiochemicals.

Evenden, M. 2016. Mating disruption of moth pests in Integrated Pest Management. A mechanist approach, pp. 365-393. In J. D. Allison and R. T. Cardé (eds.), Pheromone communication in moths: Evolution, behavior and application. University of California Press, Berkeley, California, USA.

Gaston, L. K., R. S. Kaae, H. H. Shorey, and D. Sellers. 1977. Controlling pink bollworm by disrupting sex pheromone communication between adult moths. Science 196: 904-905.

Gregg, P. C., A. P. Del Socorro, and P. J. Landolt. 2018. Advances in attack-and kill for agricultural pests: beyond pheromones. Annual Review of Entomology 63: 465-470.

Hendrichs, J., P. Kenmore, A. S. Robinson, and M. J. B. Vreysen. 2007. Area-wide Integrated Pest Management (AW-IPM): Principles, practice and prospects. pp. 3-33. In M. J. B. Vreysen, A. S. Robinson, and J. Hendrichs (eds.), Area-wide control of insect pests: From research to field implementation. Springer, Dordrecht, The Netherlands.

Higbee, B. S. 2010. NOW Areawide Projects in Kern County - Progress Report on the Lost Hills and Santa Fe navel orangeworm areawide projects - July 2010, unpublished report.

Higbee, B. S., and C. S. Burks. 2008. Effects of mating disruption treatments on navel orangeworm (Lepidoptera: Pyralidae) sexual communication and damage in almonds and pistachios. Journal of Economic Entomology 101: 1633-1642.

Higbee, B. S., and J. P. Seigel. 2009. Navel orangeworm sanitation standards could reduce almond damage. California Agriculture 63: 24-28.

Higbee, B. S., C. S. Burks, and R. T. Cardé. 2017. Mating disruption of the navel orangeworm (Lepidoptera: Pyralidae) using widely spaced, aerosol dispensers: Is the pheromone blend the most efficacious disruptant? Journal of Economic Entomology 110: 22056-2061.

Il'ichev, A. L., L. Gut, D. G. Williams, M. S. Hossain, and P. H. Jerie. 2002. Area-wide approach for improved control of the Oriental fruit moth Grapholita molesta (Busck) (Lepidoptera: Tortricidae). General and Applied Entomology 31: 7-15.

Judd, G. J. R., and M. G. T. Gardiner. 2005. Toward eradication of codling moth in British Columba by complimentary actions of mating disruption, tree banding and Sterile Insect Technique: Five-year study in organic orchards. Crop Protection 24: 718-733.

Knight, A. 2010. Improved monitoring of female codling moth (Lepidoptera: Tortricidae) with pear ester plus acetic acid in sex pheromone-treated orchards. Environmental Entomology 39: 1283-1290.

Koch, U. T., E Doye, K. Schumann, and U. Andrick. 2009. CIRCE - an addition to the toolbox for assessment / improvement of mating disruption. Pheromones and other semiochemicals. IOBC/WPRS Bulletin 41: 17-24.

Lance, D. R., D. S. Leonard, V. C. Mastro, and M. L. Waters. 2016. Mating disruption as a suppression tactic in programs targeting regulated lepidopteran pests in US. Journal of Chemical Ecology 42: 590 605 .

Liebhold, A. M. and J. Bascompte. 2003. The Allee effect, stochastic dynamics and eradication of alien species. Ecological Letters 6: 133-140. 
Linn, C. E., and W. L. Roelofs. 1986. Modulatory effects of octopamine and serotonin on male sensitivity and periodicity of response to sex pheromone in the cabbage looper moth, Trichoplusia ni. Archives of Insect Biochemistry and Physiology 3: 161-171.

Löfstedt, C., N. Walberg, and J. G. Millar. 2016. Evolutionary patterns of evolutionary diversity in Lepidoptera, pp. 43-78. In J. D. Allison and R. T. Cardé (eds.), Pheromone communication in moths: Evolution, behavior and application. University of California Press, Berkeley, California, USA.

Miller, J. R., L. J. Gut, F. M. de Lame, and L. L. Stelinski. 2006. Differentiation of competitive vs. noncompetitive mechanisms mediating disruption of moth sexual communication by point sources of sex pheromone (part I): Theory. Journal of Chemical Ecology 32: 2089-2014.

McGhee, P. S., D. L. Epstein, and L. J. Gut. 2011. Quantifying the benefits of areawide pheromone mating disruption programs that target codling moth (Lepidoptera: Tortricidae). American Entomologist 57(2): 94-100.

Onufrieva, K., S., A. D. Hickman, D. S. Leonard, and P. C. Tobin. 2018. Relationship between efficacy of mating disruption and gypsy moth density. International Journal of Pest Management 65: 44-52.

Roelofs, W. L. 2016. Reminisces of the early days, pp. 3-9. In J. D. Allison and R. T. Cardé (eds.), Pheromone communication in moths: Evolution, behavior and application. University of California Press, Berkeley, California, USA.

Roelofs, W. L., and M. A. Novak. 1981. Small-plot disruption for screening potential disruptants, pp. 229242. In E. R. Mitchell (ed.), Management of insect pests with semiochemicals. Concepts and practice. Plenum, New York, NY, USA.

Sappington, T. W., and C. S. Burks 2014. Patterns of flight behavior and capacity of unmated navel orangeworm (Lepidoptera: Pyralidae) adults related to age, gender, and wing size. Environmental Entomology 43: 696-707.

Staten, R. T., O. El-Lissy, and L. Antilla. 1996. Successful area-wide program to control pink bollworm by mating disruption, pp. 383-396. In R. T. Cardé and A. K. Minks (eds.), Insect pheromone research. New directions. Chapman Hall, New York, NY, USA.

Stern, V. M. 1979. Long and short range dispersal of the pink bollworm, Pectinophora gossypiella over southern California. Environmental Entomology 8: 524-527.

Stelinski, L. L., L. J. Gut, and J. R. Miller. 2006. Orientational behaviors and EAG responses of male codling moth after exposure to synthetic sex pheromone from various dispensers. Journal of Chemical Ecology 32: 1527-1538.

Thorpe, K., R. Reardon, K. Tcheslavskaia, D. Leonard, and V. Mastro. 2006. A review of the use of mating disruption to manage gypsy moth, Lymantria dispar (L.). United States Department of Agriculture, Forest Service, Forest Health Technology Enterprise Team (FHTET), Morgantown, West Virginia, USA. 86 pp.

Vreysen, M. J. B. 2021. Monitoring sterile and wild insects in area-wide integrated pest management programmes, pp. 485-528. In V. A. Dyck, J. Hendrichs, and A. S. Robinson (eds.), Sterile Insect Technique - Principles and practice in Area-Wide Integrated Pest Management. Second Edition. CRC Press, Boca Raton, Florida, USA.

Witzgall, P., L. Stelinski, L. Gut, and D. Thompson. 2008. Codling moth management and chemical ecology. Annual Review of Entomology 53: 503-522.

Witzgall, P., P. Kirsch, and A. Cork. 2010. Sex pheromones and their impact on pest management. Journal of Chemical Ecology 36: 80-100. 